\title{
HUBUNGAN KESEIMBANGAN DAN POWER OTOT TUNGKAI TERHADAP KEMAMPUAN TENDANGAN DOLLY CHAGI PADA ATLET UKM (UNIT KEGIATAN MAHASISWA) TAEKWONDO UNIVERSITAS BENGKULU
}

\author{
Arisman Ariansyah \\ Universitas Bengkulu \\ arizman@yahoo.co.id \\ Bayu Insanistyo \\ Universitas Bengkulu \\ Sugiyanto \\ Universitas Bengkulu
}

\begin{abstract}
Abstrak
Penelitian ini bertujuan untuk mengetahui hubungan antara keseimbangan dan power otot tungkai terhadap kemampuan tendangan Dollyo Chagi pada Atlet UKM (Unit Kegiatan Mahasiswa) Taekwondo Universitas Bengkulu. Penelitian ini merupakan penelitian korelasional dengan pendekatan cross-sectional. Sampel yang digunakan pada penelitian ini adalah mahasiswa UKM taekwondo UNIB sebanyak 18 orang. Peneliti menggunakan tekhnik pengumpulan data dengan cara melakukan tes dan pengukuran. Analisis data menggunakan analisis data korelasional. Berdasarkan hasil penelitian yang dilakukan diperoleh hasil, hubungan keseimbangan terhadap Kemampuan Tendangan Dollyo Chagi 0,62 , Hubungan power otot tungkai terhadap kemampuan tendangan dollyo chagi sebesar 0,81 sedangkan hubungan antara keseimbangan dan power otot tungkai terhadap kemampuan tendangan dollyo chagi sebesar 0,82. Dengan demikian hasil penelitian menunjukan bahwa hubungan antara keseimbangan dan power otot tungkai terhadap kemampuan tendangan dollyo chagi memiliki hubungan yang signifikan.
\end{abstract}

Kata kunci: Keseimbangan, power otot tungkai, tendangan dollyo chagi

\begin{abstract}
This study aims to determine the relationship between equilibrium and leg muscle power to the ability of kick Dollyo Chagi at the athletes of SME (Student Activity Unit) Taekwondo University of Bengkulu. This research is a correlational research with crosssectional approach. The sample used in this study is taekwondo UNIB students as many as 18 people. Researchers use data collection techniques by performing tests and measurements. Data analysis using correlational data analysis. Based on the results of the research, the results obtained, the relationship of balance to the ability to kick Dollyo Chagi0.62, Limbleg muscle power relationship to the ability kick dollyo chagiequal to 0.81 while the relationship between balance and leg muscle power to the ability kick dollyo chagi 0.82 . Thus the results showed that the relationship between equilibrium and leg muscle power to the ability of kick dollyo chagi has a significant relationship.
\end{abstract}

Keywords: balance, leg muscle power, kick dollyo chagi 


\section{PENDAHULUAN}

Taekwondo adalah warisan budaya Korea, dapat dikatakan Taekwondo sekarang dikenal sebagai seni bela diri korea yang diminati diseluruh dunia (Kim Joong Young, 2009:2). Taekwondo terdiri dari tiga kata yaitu Tae, kwon dan do. Tae berarti kaki atau menghancurkan dengan kaki, Kwon yang berarti tangan atau menghantam dan mempertahankan diri dengan tangan serta Do sebagai seni atau cara untuk mendisiplinkan diri. Maka jika diartikan secara sederhana, Tae Kwon Do berarti seni atau cara mendisiplinkan diri atau seni bela diri yang menggunakan teknik kaki dan tangan kosong.

Taekwondo mempunyai banyak kelebihan, tidak hanya mengajarkan aspek fisik semata, seperti keahlian dalam bertarung, tetapi juga menekankan pengajaran aspek disiplin mental. Dengan demikian, taekwondo akan membentuk sikap mental yang kuat dan etika yang baik bagi orang yang secara sungguh-sungguh mempelajarinya.

Taekwondo mengandung aspek filosofi yang mendalam sehingga dalam mempelajari taekwondo, pikiran, jiwa, dan raga secara menyeluruh akan ditumbuhkan dan dikembangkan, taekwondo berarti seni bela diri yang menggunakan teknik sehingga menghasilkan suatu bentuk keindahan gerakan. Tiga materi penting dalam berlatih, taekwondo adalah jurus dalam bela diri itu sendiri (Taegeuk), teknik pemecahan benda keras (Kyukpa), dan yang terakhir adalah pertarungan dalam bela diri taekwondo (Kyorugi). Mempelajari taekwondo tidak dapat hanya dengan menyentuh aspek keterampilan teknik bela diri nya saja, akan tetapi juga meliputi aspek fisik, mental dan spiritualnya agar terdapat keseimbangan diantaranya. Untuk itu, seorang taekwondoin dalam berlatih taekwondo sudah seharusnya menunjukkan kondisi fisik yang prima, mental kuat dan semangat yang tinggi agar dalam pelaksanaan memiliki keseimbangan di dalamnya. Teknik tendangan merupakan gerakan melecutkan kaki yang didahului dengan menekukkan lutut dengan sudut 90 derajat.

Menurut Farida Yuni Susilowati (2005: 6) teknik tendangan adalah cara yang dilakukan untuk menyerang maupun bertahan dengan menggunakan tungkai/kaki. Dilakukan dengan mengangkat lutut setinggi mungkin dengan dada, kemudian melentingkan atau menyodokkan kaki yang akan digunakan untuk menendang. Ada dua cara dalam melakukan teknik tendangan, cara pertama adalah dengan melentingkan lutut (snap), cara kedua ialah dengan menyodok (thrust). Farida Yuni Susilowati (2005: 6), mengatakan ketangkasan menggunakan kaki juga merupakan kepandaian yang utama maksudnya adalah serangan dengan tendangan. Teknik tendangan dalam olahraga beladiri taekwondo yang baik dipengaruhi oleh posisi kaki, keseimbangan badan, pinggang, dan sudut saat mengangkat lutut, agar mendapatkan hasil ledakan yang keras dan tepat sasaran.

V. Yoyok Suryadi (2002: 33-39) mengutarakan ada berbagai macam tendangan, diantaranya:

1) Ap Chagi (Tendangan Depan)

Tendangan dengan sentakan lutut kearah depan menggunakan bantalan telapak kaki bagian depan (ap chuk).

2) Dollyo Chagi (Tendangan Serong/Memutar) Kekuatan tendangan ini selain dari lecutan lutut juga sangat didukung oleh putaran pinggang yang sebenarnya merupakan penyaluran tenaga dari masa badan. Tendangan ini pada dasarnya menggunakan pula bantalan telapak kaki (ap chuk) atau baldeung (punggung kaki).

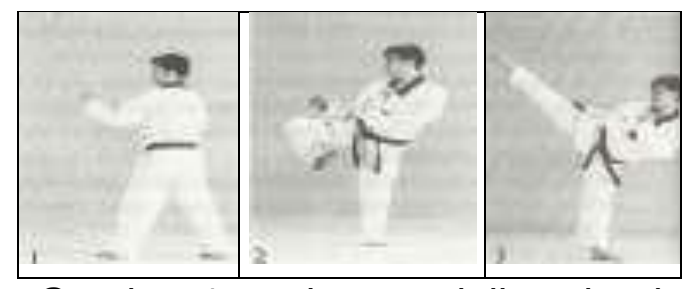

Gambar 1 tendangan dollyo chagi 3) Yeop Chagi (Tendangan Samping) 
Tendangan samping yang memerlukan kontraksi badan saatmemindahkan tenaga ke sasaran, sehingga diperoleh tenaga hentak atau dorong yang maksimal. Tendangan ini menggunakan pisaukaki (balnal) ataupun tumit (dwi chuk).

4) Dwi Chagi (Tendangan Belakang)

Tendangan belakang dilakukan dengan langsung menendang ke belakang untuk lawan yang berada di belakang kita seperti menyepak kebelakang.

5) Naeryo Chagi (Tendangan

Menurun/Mencangkul)

Tendangan ini dapat dilakukan dengan mengangkat kaki setinggi mengkin lewat luar, dalam, atau langsung ke atas (depan), dan dijatuhkan sekuat mungkin ke arah sasaran.

6) Twio Yeop Chagi (Tendangan Samping Dengan Melompat)

Tendangan ini adalah variasi dari tendangan samping (yeop chagi) yang dilakukan dengan loncatan.

7) Dwi Huryeo Chagi (Tendangan Serong Belakang)

Sering disebut juga secara singkat dwi hurigi, tendangan ini merupakan perpaduan atau kombinasiantara dwichagi (tendangan ke belakang) dan mom dollyo chagi (kebalikan tendangan serong).

8) Dubal Dangsang Chagi (Nare Chagi)

Tendangan ini adalah variasi dari tendangan dengan dua target sasaran pertama lebih rendah dibandingkan sasaran kedua.

9) Twio Ap Chagi (Tendangan Kedepan Dengan Loncatan)

Tendangan ini adalah variasi dari tendangan depan hanya didahului dengan loncatan

10) Two Dwi Chagi (Tendangan Kebelakang Dengan Meloncat)

Tendangan ini adalah variasi dari tendangan belakang (dwi chagi) yang dilakukan sambil meloncat dan memutar tubuh 360 derajat.
Salah satu keterampilan yang sangat penting dalam olahraga adalah kemampuan untuk mempertahankan keseimbangan dalam berbagai macam posisi karena akan menentukan hasil akhir setiap gerak yang dilakukan (Putut, 1998: 46). Menurut

Soedarminto (1992: 152-153) stabilitas yang dimaksud disini adalah tingkat keseimbangan. Semua objek yang diam dikatakan dalam keadaan seimbang. Semua gaya yang bekerja padanya seimbang, jumlah gaya-gaya linear yang bekerja sama dengan nol dan jumlah semua momen sama dengan nol. Tetapi, tidak semua objek yang diam memiliki stabilitas yang sama. Jika posisi sebuah objek diubah sedikit dan objek itu cenderung untuk kembali pada posisi semula, maka objek itu dalam keadaan seimbang stabil atau seimbang mantap.

Menurut Harsono (1988:24) power adalah produk dari kekuatan dan kecepatan. Power adalah kemampuan otot untuk mengarahkan kekuatan maksimal dalam waktu yang amat singkat. Sedangkan menurut Sukadiyanto (2011:117) poweradalah hasilkali antarakekuatan dankecepatan. Artinyabahwa latihan kekuatan dan kecepatan sudah dilatihkan terlebih dahulu, walaupun dalam setiap latihan kekuatan dan kecepatan sudah ada unsur latihan power.

Menurut Syaifudin (1996:60) bahwa tungkai terdiri atas tungkai atas, yaitu pangkal paha sampai lutut, dan tungkai bawah yaitu lutut sampai pergelangan kaki. Dari uraian di atas dapat diartikan bahwa kekuatan otot tungkai adalah komponen kondisi fisik yang menyangkut masalah kemampuan mengangkat atau menahan beban seorang atlet pada saat menggunakan otot tungkai atau kaki. Secara keseluruhan tulang tungkai berjumlah 31 buah, yaitu: 1 os koxsa (tulang pangkal paha), 1 os femur (tulang paha), 1 os tibia (tulang kering), 1 os fibula (tulang betis), 1 os patella (tulang lutut), 7 os tarsal (tulang pergelangan kaki), 5 os metatarsalia (tulang telapak kaki), 14 os falang (tulang jari-jari 
kaki).untuk menempuh suatu jarak dalam waktu yang sesingkat-singkatnya.

\section{METODE}

Penelitian ini merupakan penelitian korelasional dengan pendekatan crosssectional. Pendekatan ini adalah strategi penelitian dimana subyek hanya diobservasi sekali saja dan pengukuran variabel dilakukan pada saat penelitian (Notoatmojo, 2010).

Sampel yang digunakan pada penelitian adalah mahasiswa UKM taekwondo UNIB sebanyak 18 orang. Sampel akan diperoleh dengan menggunakan sistem purposive sampling. Menurut Sugiyono (2007: 85) purposive sampling adalah teknik penentuan sampel dengan pertimbangan tertentu. Adapun pertimbangan untuk sampel penelitian ini sebagai berikut:

1) Jenis kelamin laki-laki

2) Bersedia mengikuti prosedur penelitian

3) Sehat jasmani dan rohani

4) Bersedia menjadi sampel penelitian

Variabel penelitian dalam penelitian ini terdiri dari 2 variabel bebas (Independent) dan satu variabel terikat (dependent) dengan rincian yaitu: Keseimbangan, Power Otot Tungkai dan kemampuan tendangan dollyo chagi.

Dalam penelitian ini data diperoleh dengan cara tes dan pengukuran. Pelaksanaan tes dilakukan ditempat Latihan UKM taekwondo UNIB. Instrumen yang digunakan dalam penelitian untuk pengumpulan data ini ada 3 macam, yaitu: Dynamic Test of Positional Balance untuk mengukur keseimbangan, Tes Standing Broad Jump untuk mengukur kekuatan otot tungkai dan Tes Kemampuan Tendangan Dollyo Chagi untuk mengukur kemampuan tendangan.

Analisis data dalam penelitian ini adalah korelasi, korelasi parsial dan regresi berganda. Teknik analisis korelasi yang dimaksud adalah analisis statistik untuk mengetahui apakah ada keterkaitan antar variabel bebas dan variabel terikat dalam penelitian, maka dilakukan analisis korelasi Analisis korelasi parsial adalah suatu statistik parametrik yang digunakan untuk menguji taraf hubungan antar variabel bebas dengan variabel terikat pada kondisi variabel bebas yang lain sebagai variabel yang fungsinya untuk memurnikan hubungan antar variabel bebas dengan variabel terikat tersebut.

Menurut Ali Maksum (2012: 172) analisis regresi ganda digunakan untuk menelaah hubungan antar dua variabel atau lebih, terutama untuk menelusuri pola hubungan yang modelnya belum diketahui secara sempurna, atau untuk mengetahui bagaimana variasidaribeberapa variabel bebas (X1), (X2), (X3) ... (Xa) mempengaruhi variabel terikat dalam suatu fenomena yang kompleks.

\section{HASIL DAN PEMBAHASAN}

\section{Hasil}

Berdasarkan hasil ketiga tes yaitu keseimbangan dan power otot tungkai terhadap Kemampuan Tendangan Dollyo Chagi Pada Atlet UKM (Unit Kegiatan Mahasiswa) Taekwondo Universitas Bengkulu, maka diperoleh nilai rata-rata, nilai maksimal dan nilai minimal yang diperoleh peserta pada masing-masing item tes yang dilakukan. Untuk lebih jelasnya dapat diperhatikan pada tabel dibawah ini :

Tabel 1. Rekapitulasi Tes

\begin{tabular}{|c|c|c|c|c|c|}
\hline \multicolumn{2}{|c|}{$\begin{array}{c}\text { Tes } \\
\text { Keseimbangan }\end{array}$} & \multicolumn{2}{|c|}{$\begin{array}{c}\text { Power Otot } \\
\text { Tungkai }\end{array}$} & \multicolumn{2}{|c|}{$\begin{array}{l}\text { Tendangan } \\
\text { Dollyo chagi }\end{array}$} \\
\hline$\sum X_{1}$ & 1382 & $\sum X 2$ & 3861 & $\sum Y$ & 434 \\
\hline Max & 83 & Max & 225 & Max & 29 \\
\hline Min & 70 & Min & 200 & Min & 18 \\
\hline
\end{tabular}

\section{Keterangan :}

$\Sigma X 1=$ Nilai rata-ratakeseimbangan

$\sum X 2=$ Nilai rata-rata power otot tungkai

$\Sigma Y=$ Nilai rata-rata tendangan dollyo chagi

Max =Nilai Maximum (Nilai Tertinggi)

Min =Nilai Minimum (Nilai Terendah). 


\section{Pembahasan}

Penelitian ini bertujuan untuk mengetahui hubungan antara keseimbangan dan power otot tungkai terhadap kemampuan tendangan dollyo chagi. Secara teori dalam melakukan tendangan dollyo chagi ditentukan beberapa aspek biomotorik sepertikekuatan, kecepatan, kelenturan, keseimbangan dan daya ledak. Aspek lain adalah adanya postur tubuh yang ideal. Akan tetapi yang menjadi focus dalam penelitian ini adalah aspek psikomotor khususnya mengenai keseimbangan dan power otot tungkai.

1. Hubungan Keseimbangan Terhadap

Kemampuan Tendangan Dollyo Chagi

Berdasarkan dari hasil pengujian yang telah dilakukan sebelumnya bahwa ada hubungan yang signifikan antara Keseimbangan Terhadap Kemampuan Tendangan Dollyo Chagi pada atlet UKM (Unit Kegiatan Mahasiswa) Taekwondo Universitas Bengkulu. Pada saat gerak tendangan dollyoChagi posisi keseimbangan termasuk dalam bagian keseimbangan yang baik pada posisi kuda-kuda tegap. Karena tumpuan pelaksanaan gerak serang pada satu kaki. Pemain akan selalu memperoleh keseimbangan baru dalam setiap perubahan gerak yang terjadi.

Faktor-faktor yang mempengaruhi stabilitas (keseimbangan tubuh) adalah 1) Tingginya titik berat, 2) Letak garis berat, 3) Luas dasar penumpu, 4) Massa objek, 5) Gesekan, 6) Posisi segmen-segmen badan, 7) Penglihatan dan psikologis, dan 8) Fisiologis (Soedarminto 1992: 301-307). Sehingga dapat disimpulkan bahwa semakin baik keseimbangan seseorang maka semakin baik pula dalam melakukan kemampuan tendangan dollyo chagi pada atlet UKM (Unit Kegiatan Mahasiswa) Taekwondo Universitas Bengkulu.

Hal ini didasarkan rhitung sebesar 0,62 sedangakan rtabel pada $\alpha=5 \%$ dan $\mathrm{dk}=\mathrm{n}-2=$ $18-2=16$ adalah 0,468 yaitu 0,62 >0,468. sedangkanttabel pada $\alpha=5 \%$ adalah 2,100 . Di peroleh thitung $>$ ttabel yaitu 3,13 > 2,100 yang berarti ada hubungan yang signifikan.

2. Hubungan Power Otot Tungkai Terhadap Kemampuan Tendangan Dollyo Chagi.

Berdasarkan dari hasil pengujian yang telah dilakukan sebelumnya bahwa ada hubungan yang signifikan antara Power Otot Tungkai Terhadap Kemampuan Tendangan Dollyo Chagi pada atlet UKM (Unit Kegiatan Mahasiswa) Taekwondo Universitas Bengkulu.

Power otot tungkai merupakan salah satu unsur pendukung meningkatnya performance atlet dalam setiap aktivitas bertanding. Hal senada juga dikemukakan oleh pendapat Harsono (1988), bahwa dengan memiliki power tungkai maka seorang atlet akan mampu meningkatkan kemampuan fisiknya yang secara lansung dapat menunjang penguasaan teknik - teknik pada saat situasi pertandingan seperti hal nya pada saat akan melakukan tendangan dollyo chagi pada olahraga taekwondo. Pendapat lain dikemukakan oleh Suharno, HP (1984), Yang mengemukakan bahwa dengan memiliki power yang baik seorang atlet akan mampu melakukan unjuk kerja yang maksimal dan eksplosif yang dilakukan dalam waktu yang singkat semisal pada saat melepaskan tendangan dollyo chagi dalam olahraga taekwondo, Sehingga dapat disimpulkan

bahwa semakin baik power otot tungkai seseorang maka semakin baik pula dalam melakukan kemampuan tendangan dollyo chagi pada atlet UKM (Unit Kegiatan Mahasiswa) Taekwondo Universitas Bengkulu. Hal ini didasarkan rhitung sebesar 0,81 sedangakan rtabel pada $\alpha=5 \%$ dan $\mathrm{dk}=\mathrm{n}-2=$ $18-2=16$ adalah 0,498 yaitu $0,81>0,468$. sedangkan ttabel pada $\alpha=5 \%$ adalah 2,100 . diperoleh thitung $>$ ttabel yaitu 5,62 > 2,100 yang berarti ada hubungan yang signifikan. 3. Hubungan Keseimbangan dan Power Otot Tungkai Terhadap kemampuan tendangan dollyo chagi.

Berdasarkan dari hasil pengujian yang telah dilakukan sebelumnya bahwa ada hubungan yang signifikan antara keseimbangan dan 
power otot tungkai terhadap kemampuan tendangan dollyo chagi pada atlet UKM (Unit Kegiatan Mahasiswa) Taekwondo Universitas Bengkulu, dapat disimpulkan bahwa semakin baik keseimbangan dan power otot tungkai seseorang maka semakin baik pula dalam melakukan kemampuan tendangan dollyo chagi.

Hal tersebut terbukti bahwa semakin baik keseimbangan dan power otot tungkai seseorang maka semakin baik pula kemampuan tendangan dollyo chagi nya, dibandingkan yang keseimbangan dan power otot tungkai yang rendah, oleh sebab itu ukuran baik tidaknyakeseimbangandan power otot tungkai seseorang akan menunjang kemampuan tendangan dollyo chagi.

Dari hasil penelitian ini maka diketahui bahwa adanya hubungan keseimbangan dan power otot tungkai terhadap kemampuan tendangan dollyo chagi nya sebesar 0,82 . Jadi nilai rhitung sebesar 082, sedangakan rtabel pada $\alpha=5 \%$ dan $\mathrm{dk}=\mathrm{n}-2=18-2=16$ adalah 0,468 yaitu $0,82>0,468$. sedangkan ttabel pada $\alpha=5 \%$ adalah 2,100. diperoleh thitung > ttabel yaitu 2,24 > 2,100 yang berarti ada hubungan yang signifikan.

\section{PENUTUP}

\section{Simpulan}

Berdasarkan pada uraian hasil pembahasan dalam penelitian ini serta dari pengolahan data yang telah dilakukan maka dapatlah diambil suatu kesimpulan sebagai berikut:

1. Ada hubungan keseimbangan terhadap Kemampuan Tendangan Dollyo Chagi pada atlet UKM (Unit Kegiatan Mahasiswa) Taekwondo Universitas Bengkulu. sebesar 0,62 sedangkan rtabel pada $\alpha=5 \%$ dan dk $=$ $\mathrm{n}-2=18-2=16$ adalah 0,498 yaitu $0,62>$ 0,468 . sedangkan ttabel pada $\alpha=5 \%$ adalah 2,100. diperoleh thitung $>$ ttabel yaitu 3,31 $>2,100$ yang berarti ada hubungan yang signifikan.
2. Ada hubungan power otot tungkai terhadap kemampuan tendangan dollyo chagi pada atlet UKM (Unit Kegiatan Mahasiswa) taekwondo Universitas Bengkulu sebesar 0,81 sedangakan rtabel pada $\alpha=5 \%$ dan $\mathrm{dk}$ $=\mathrm{n}-2=18-2=16$ adalah 0,498 yaitu $0,81>$ 0,468 . sedangkan ttabel pada $\alpha=5 \%$ adalah 2,100. diperoleh thitung $>$ ttabel yaitu 5,56 $>2,100$ yang berarti ada hubungan yang signifikan.

3. Ada hubungan antara keseimbangan dan power otot tungkai terhadap kemampuan tendangan dollyo chagi pada atlet UKM (Unit Kegiatan Mahasiswa) taekwondo Universitas Bengkulu sebesar 082, sedangakan rtabel pada $\alpha=5 \%$ dan $\mathrm{dk}=\mathrm{n}$ $2=18-2=16$ adalah 0,498 yaitu 0,49 > 0,468 . sedangkanttabel pada $\alpha=5 \%$ adalah 2,100. diperoleh thitung $>$ ttabel yaitu 2,24 $>2,100$ yang berarti ada hubungan yang signifikan.

\section{Saran}

Berdasarkan pada hasil penelitian dan kesimpulan yang telah disebutkan diatas, maka timbul beberapa wawasan yang dikemukakan oleh peneliti berupa saran-saran diantaranya adalah sebagaaiberikut:

1. Bagi pelatih taekwondo kiranya dalam melatih atlet memperhatikan unsur biomotorik keseimbangan dan power otot tungkai khususnya dalam melatih teknik dasar tendangan dollyo chagi

2. Bagi atlet pada umumnya dan khususnya atlet UKM (Unit Kegiatan Mahasiswa) taekwondo Universitas Bengkulu sebesar, disarankan dapat meningkatkan kemampuan nya dalam melakukan tendangan dollyo chagi.

3. Disarankan kepada peneliti lain yang akan melakukan penelitian yang relevan dengan penelitian ini kiranya dapat mengungkap hubungan kemampuan fisik lain khusunya dalam menunjang kemampuan tendangan dollyo chagi. 


\section{DAFTAR PUSTAKA}

Harsono. (1988). Coaching dan Aspek- Aspek Psikologi Dalam Coaching. Jakarta: Departemen Pendidikan dan Kebudayaan.

Marhento, Putut. (2000). Majalah Ilmiah Olahraga. Yogyakarta: MAJORA Volume 6 Edisi April 2000.

Notoatmodjo, Soekidjo. (2010). Metodologi Penelitian Kesehatan. Jakarta: P.T Rineka Cipta.

Nurhasan. (2007). Tes dan Pengukuran Keolahragaan. Bandung: IKIP

Soedarminto. (1992). Kinesiologi. Jakarta; DEPDIKBUD DIRJEN DIKTI

Suharno HP. (1993). Metodologi Pelatihan. Yogyakarta: IKIP Yogyakarta

Sugiyono. (2007). "Metode Penelitian Kuantitatif Kualitatif Dan $R$ \& $D$ ". Bandung: Alfabeta.

Sukadiyanto. (2002). Teori Metodologi Melatih Fisik Petenis. Yogyakarta: FIK UNY

Suryadi, Yoyok V. (2002). Poomsae Taekwondo untuk Kompetisi. Jakarat: PT Gramedia Pustaka Utama.

Syaifudin, B. Ac, (1996). Anatomi Untuk Siswa Perawat. Jakarta: Balai Pustaka 